\title{
Genetic control of the pre-reproductive period in Autographa gamma (L.) (Silver Y moth) (Lepidoptera: Noctuidae)
}

\author{
J. K. HILL \& A. G. GATEHOUSE \\ School of Biological Sciences, University of Wales, Bangor, Gwynedd LL57 2UW, U.K.
}

\begin{abstract}
Adults of the noctuid moth Autographa gamma undertake seasonal migrations into areas where they are unable to breed continuously. Individuals migrate into Britain each spring and offspring of these migrants probably return in autumn to over-wintering areas in North Africa and the Middle East, although the existence of these return migrations has been questioned. Insects usually migrate during the adults' pre-reproductive period (PRP). The length of this period is therefore an index of migratory potential because individuals with longer PRPs have more time to express their potential for flight and to travel further. Significant, positive full-sib correlations showed that female offspring with long PRPs came from families where their brothers had correspondingly long PRPs. This suggests that the same genes control the rate of reproductive development in both sexes. There was a rapid response to selection for short and long PRP, with separation of the lines by the second generation of selection. Sib-analysis and parent-offspring regressions showed that the genes with the greatest influence on PRP are X-linked, although there is also an autosomal influence. The significance of $\mathrm{X}$-linkage of genes controlling the PRP is discussed in relation to the migratory strategy of $A$. gamma.
\end{abstract}

Keywords: adult diapause, Autographa gamma, migration, X-linkage.

\section{Introduction}

Autographa gamma is a common migratory species which is distributed throughout the holarctic (Balachowsky, 1972). Adults undertake seasonal, northward migrations to areas where they are unable to breed continuously. Individuals migrate into Britain each spring and, after one, two or three generations, descendants of the spring migrants probably return to over-wintering sites in North Africa and the Middle East (Fisher, 1938). The existence of return migrations, however, has been questioned (Rabb \& Stinner, 1978; Stinner et al., 1983).

Migration in insects usually takes place during the pre-reproductive period (PRP) of adult life (Johnson, 1969). In migratory noctuid moths, the incidence of prolonged flight greatly decreases with the onset of sexual maturity (Han \& Gatehouse, 1993; Colvin \& Gatehouse, 1993). The length of the PRP (the time between adult emergence and attainment of sexual maturity) is therefore an index of migratory potential

Correspondence: Dr J. K. Hill, School of Biological Sciences, University of Wales, Bangor, Gwynedd LL57 2UW, U.K. because it determines the interval over which individuals can express their capacity for flight. In some noctuid species there is great variation in the length of the PRP (Turgeon \& McNeil, 1983; Han \& Gatehouse, 1991a), with individuals with longer PRPs having the potential to travel further.

Factors affecting migratory potential have been shown to be genetically controlled in many insect species. These include flight capacity (Caldwell \& Hegmann, 1969; McAnelly, 1985; Parker \& Gatehouse, 1985; Palmer \& Dingle, 1989) and wing length (Palmer \& Dingle, 1986; Dingle \& Evans, 1987). Genetic control of the length of the PRP has also been demonstrated (Colvin, 1990; Han \& Gatehouse, 1991a; Wilson \& Gatehouse, 1992). Many of these characters vary continuously and are therefore under polygenic control, resulting from the action of genes at several loci (Falconer, 1989).

The length of the PRP is strongly influenced by genes on the $\mathrm{X}$ chromosome in the noctuid species Mythimna separata (Han \& Gatehouse, 1991a), Heliothis armigera (Colvin, 1990) and Spodoptera exempta (Wilson \& Gatehouse, 1992). Females are the heterogametic (XY) sex in Lepidoptera and, therefore, 
obtain their single $\mathrm{X}$ chromosome from their homogametic (XX) fathers. Females of the above species therefore obtain the majority of genes controlling PRP from their fathers and any resemblance between daughters and mothers is due to autosomal influences and non-genetic maternal effects.

Modelling rates of evolution, Charlesworth et al., (1987) have suggested a number of important consequences of X-linkage of traits, which may have important implications for the control of migration in noctuids (Han \& Gatehouse, 1991a). This paper investigates the genetic control of PRP in A. gamma, using full-sib correlations, sib-analysis, parentoffspring regressions and selection experiments. Sibanalysis experiments and parent-offspring regressions are used to determine the mode of inheritance of PRP, i.e. whether the major influence is from autosomal or $\mathrm{X}$-linked genes. The implications of X-linkage of genes controlling PRP are discussed for the regulation of migration in this species.

\section{Materials and methods}

\section{Insect material}

Moths were obtained from three sources: over 50 adults were trapped in Bangor, North Wales during the summer and autumn of 1988 and 1989; over 100 adults were collected from Morocco in 1989 and 1990; over 30 adults were collected from Sweden in 1989. Experiments used $G_{1}$ offspring from Moroccan and Swedish insects and $G_{2}$ and $G_{3}$ offspring from British insects. Larvae in all treatments were reared in $500 \mathrm{ml}$ glass 'Kilner' jars with filter paper lids and were provided with an excess of either turnip (Brassica rapa), dandelion (Taraxacum officinale) or Chinese leaves (Brassica chinensis). Cut ends of leaves were placed in vials of water within the jars to retard wilting and any wilting leaves and frass were removed on a daily basis. Larvae were maintained at a density of approximately 80 per jar for the first two instars. Densities were reduced to 15 larvae per jar at the third instar and further reduced to six larvae per jar for the final instar. Once the larvae had pupated and their cuticles hardened (usually 1 day after pupation), they were removed from their silk cocoons. Pupae were sexed according to the position of the genital pore of the last abdominal segment and were placed in individual 50 ml plastic pots, which were checked regularly for newly emerged adults.

\section{Measuring PRP in females}

On reaching sexual maturity, females release a sex pheromone to attract males. This 'calling' behaviour can commence at any time throughout the scotophase (Hill, 1991) and can be easily recognized because females fan their wings whilst they extrude their ovipositor from the tip of the abdomen. Single, newly emerged females were transferred to $300-\mathrm{ml}$ clear plastic containers provided with 10 per cent sugar solution. They were observed throughout the scotophase for the onset of calling using a pen-light torch fitted with a red filter $(600-1200 \mathrm{~nm})$. PRP was defined as the number of nights from emergence to first call.

\section{Measuring PRP in males}

Males respond to calling females by everting their abdominal brushes and clasping the tip of the female's abdomen. They can respond to female sex pheromone throughout the scotophase (Szocs \& Toth, 1979). Males were introduced into a netting cage containing at least two calling females and their behaviour was observed. Males were tested at least twice during the scotophase and between test occasions they were kept in incubators away from calling females to prevent the possibility of sensory fatigue to pheromone detection. Females were used only if they had recently started to call because the release of pheromone declines rapidly during a calling bout (Bjostad et al., 1980). Males that mated or attempted to mate, with their brushes everted, were scored as sexually mature. PRP was defined as the number of nights from emergence until the first attempt to mate. Adults were provided with 10 per cent sugar solution from the night of emergence.

\section{Comparison of PRPs between sexes and full-sib correlations}

Male and female offspring from Moroccan, British and Swedish insects were reared at $20^{\circ} \mathrm{C} \pm 1^{\circ} \mathrm{C}$ under a photoperiod of 16L:8D. Male and female PRPs were measured as above. For full-sib correlations, at least 10 males and 10 females were reared from each of 10 pairs of Moroccan adults, plus nine British pairs and six Swedish pairs.

\section{Selection for long and short PRPS}

Two selection experiments were performed. In the first experiment, a line selected for early reproductive maturity was established from six British females with PRPs of one or two nights. A line selected for late maturity was also established, from 10 British females with PRPs of four nights or longer. These selection criteria were maintained for two generations, with 
females being mated to males from their selected line. Selection was carried out solely on the basis of female PRP and the PRPs of males in the parental generations were unknown.

In the second experiment, an early-maturing line was established from 13 Moroccan females with PRPs of one or two nights and a late-maturing line was established from 16 Moroccan females with PRPs of four nights or longer. Selection was again carried out solely on the basis of female PRP but, unlike the previous experiment, early and late-developing families were identified in the parental generation on the basis of female PRPs. Females in the parental generation were then mated to males from these early and late-developing families to establish early and late lines. In both experiments, females were observed for the onset of calling at $16^{\circ} \mathrm{C} \pm 1^{\circ} \mathrm{C}$ under a photoperiod of 12L:12D.

\section{Mode of inheritance of PRP}

This was investigated by a sib-analysis experiment and by parent-offspring regressions. In sib-analysis experiments, several males are each mated randomly to several females and the character under study is then measured in the offspring of each mother (Falconer, 1989). If the character is disproportionately affected by genes on the $\mathrm{X}$ chromosome, the homogametic $(\mathrm{XX})$ parent will have a large influence on the expression of the trait in its heterogametic (XY) offspring, whereas the $X Y$ parent will have little influence on its $X Y$ offspring. For autosomally inherited characters, a significant proportion of the phenotypic variance of $\mathrm{XY}$ offspring will be attributable to both mothers and fathers.

Sib-analysis. Thirty-three males from 17 families were mated, each to two different females whose PRPs were known. PRPs of mothers and their female offspring were measured at $16^{\circ} \mathrm{C} \pm 1^{\circ} \mathrm{C}$ under a photoperiod of 12L:12D. PRPs of fathers were not known.

Parent-offspring regressions. Female offspring were reared from 21 pairs of adults where the PRP of the mother (but not of the father) was known. Male offspring were also reared from 11 of these pairs. PRPs were measured for mothers and for male and female offspring at $20^{\circ} \mathrm{C} \pm 1^{\circ} \mathrm{C}$ under a photoperiod of $16 \mathrm{~L}: 8 \mathrm{D}$.

\section{Data analysis}

Data were tested for normality and the appropriate parametric or non-parametric analyses were per- formed. Heritability estimates of PRP and their standard errors were calculated from the slopes of regression lines of offspring upon parents (Falconer, 1989).

\section{Results}

\section{Male and female PRPs and full-sib correlations}

Median PRPs of Moroccan males and females were. three and one nights, respectively (Table 1). This difference is highly significant (Medians test for 266 cases, chi-square $=121.97,1$ d.f., $P<0.001$ ). The median PRP of Swedish males was also significantly longer than that of females (Table 1; medians test for 146 cases, chi-square $=27.57,1$ d.f., $P<0.001$ ). There was no significant difference between the median PRPs of British male and female moths (Table 1; medians test for 185 cases, chi-square $=2.60,1$ d.f., $P=0.11$ ). There was a significant, positive correlation between the mid-PRP value (calculated as the sum of PRPs divided by the sample size) of males and females from the 10 Moroccan families (Spearman rank-order correlation $\left.r_{\mathrm{s}}=0.602, n=10, P=0.033\right)$ and also for the nine British families $\left(r_{\mathrm{s}}=0.814, N=9, P=0.004\right)$, but not for the six Swedish families $\left(r_{s}=-0.232\right.$, $N=6, P=0.329$ ).

\section{Selection experiments}

A rapid response to selection was observed in both experiments. Separation of the lines for British offspring did not occur until the second generation(Fig. 1; Mann-Whitney $U$-test corrected for ties; $G_{1}$ generation, $U=372.5, N=60, P=0.89 ; \mathrm{G}_{2}$ generation,

Table 1 PRPs of male and female offspring of A. gamma derived from insects collected in Morocco, Britain and Sweden

\begin{tabular}{lccc}
\hline & Morocco & Britain & Sweden \\
\hline Female & & & \\
Median & 1 & 2 & 2 \\
Q1-Q3 & $1-2$ & $2-3$ & $2-2$ \\
Range & $1-4$ & $1-5$ & $1-4$ \\
$N$ & 170 & 153 & 78 \\
Male & & & \\
Median & 3 & $2-3$ & $2-3$ \\
Q1-Q3 & $2.25-3$ & $2-3$ & $2-5$ \\
Range & $2-6$ & $1-4$ & 68 \\
$N$ & 96 & 32 & \\
\hline
\end{tabular}

$N=$ sample size, $\mathrm{Q} 1-\mathrm{Q} 3=$ interquartile distance. 


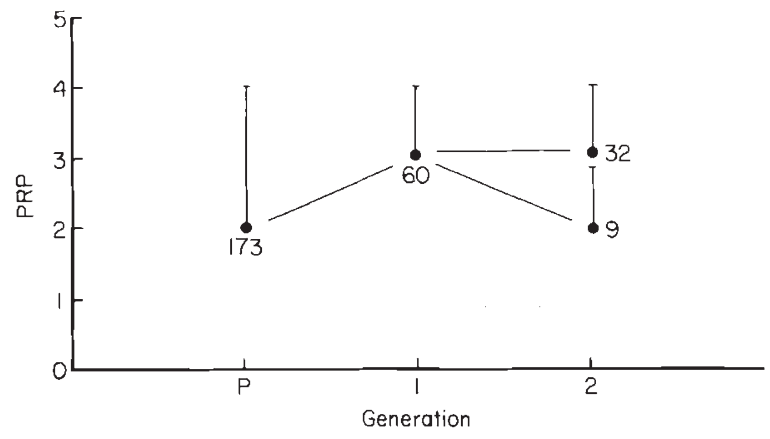

Fig. 1 Selection for early and late reproductive development in British $A$. gamma. There was a significant difference between median PRPs in the two lines by the $\mathrm{G}_{2}$ generation (Mann-Whitney-test for 41 cases, $U=52, P=0.003$; early line, median $=2, \mathrm{Q} 1-\mathrm{Q} 3=2-3, N=9$; late line, median $=3$, $\mathrm{Q} 1-\mathrm{Q} 3=3-4, N=32$ ). Medians and interquartile distances are shown. Numbers by medians give sample sizes.

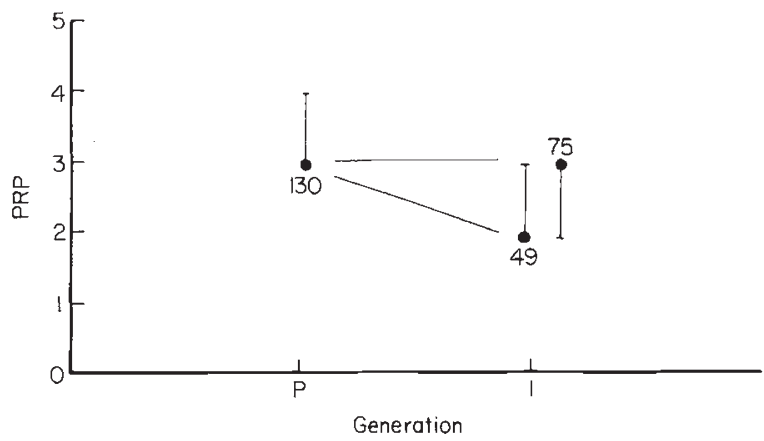

Fig. 2 Selection for early and late reproductive development in Moroccan A. gamma. There was a significant difference in the median PRPs of females in the early-and late-developing lines by the first generation (Mann-Whitney U-test for 124 cases, $Z=-2.04, P=0.041$; early line, median $=2$, $\mathrm{Q} 1-\mathrm{Q} 3=2-3, N=49$; late line, median $=3, \mathrm{Q} 1-\mathrm{Q} 3=2-3$, $N=75$ ). Medians and interquartile distances are shown. Numbers by medians give sample sizes.
$U=52.0, n=41, P=0.003)$. Separation of the two selected lines for Moroccan offspring occurred in the first generation (Fig. 2; Mann-Whitney $U$-test corrected for ties, $Z=-2.04, N=124, P=0.041)$. In both experiments the insect cultures were lost due to viral disease after relatively few generations.

\section{Sib-analysis experiment}

Thirty-three males were mated, each to two females. PRPs were recorded for 95 offspring, from five males which each produced five or more offspring from each female. PRPs of these offspring are shown in Table 2. In all other cases a male's second mating was either infertile or produced offspring which succumbed to disease before pupation. Nested ANOVA revealed a significant between-fathers component of variation $(F=7.09,85$ and 4 d.f., $P=0.027$ ) but no significant betweenmothers (within-fathers) component of variation $(F=0.58,85$ and 5 d.f., $P=0.717)$. This shows that female PRP is influenced mostly by genes received from their fathers, and hence that there is a substantial influence of genes located on the X-chromosome.

\section{Parent-offspring regressions}

Weighted regression analysis revealed a significant, positive regression of mean PRP of sons on maternal PRP $\left(r^{2}=0.47,10\right.$ d.f., $\left.P=0.021\right)$. The regression line is described by the equation:

$y=1.73($ S.E. $=0.35)+0.328 \bar{x}($ S.E. $=0.117)$

where $y$ is the mean PRP of sons and $x$ is the maternal PRP. There was also a significant, positive regression of the mean PRP of daughters on maternal PRP $\left(r^{2}=0.31,20\right.$ d.f., $\left.P=0.008\right)$. The regression line is

Table 2 Results of a sib-analysis experiment to investigate the mode of inheritance of PRP in A. gamma

\begin{tabular}{|c|c|c|c|c|c|c|c|c|c|c|}
\hline & \multicolumn{10}{|l|}{ Sire } \\
\hline & \multicolumn{2}{|l|}{1} & \multicolumn{2}{|l|}{2} & \multicolumn{2}{|l|}{3} & \multicolumn{2}{|l|}{4} & \multicolumn{2}{|l|}{5} \\
\hline Dam & A & B & A & B & A & B & A & B & A & B \\
\hline PRP & 1 & 1 & 2 & 5 & 3 & 5 & 1 & 5 & 6 & 6 \\
\hline \multicolumn{11}{|c|}{$\mathrm{F}_{1}$} \\
\hline Mean PRP & 1.64 & 1.57 & 2.21 & 2.40 & 2.17 & 2.80 & 2.00 & 2.27 & 3.60 & 4.00 \\
\hline Range & $1-4$ & $1-2$ & $2-3$ & $1-4$ & $2-3$ & $2-4$ & $1-5$ & $1-3$ & $3-6$ & $3-6$ \\
\hline$N$ & 11 & 7 & 14 & 15 & 6 & 5 & 14 & 11 & 5 & 7 \\
\hline
\end{tabular}

$N=$ sample size, $\mathrm{PRP}=$ pre-reproductive period. 
described by the equation:

$y=1.85($ S.E. $=0.13)+0.122 \bar{x}($ S.E. $=0.041)$

where $y$ is the mean PRP of daughters and $x$ is the maternal PRP. The two regression lines were not significantly different at the 5 per cent level (weighted multiple regression testing the significance of the interaction between male and female offspring, $F$ change $=3.55,1$ and 28 d.f., $P=0.070)$. Narrow-sense heritability estimates $\left(h^{2}\right)$ of PRP, calculated from the slopes of the regression lines (Falconer, 1989), were $0.656 \pm 0.234$ for sons on mothers and $0.244 \pm 0.082$ for daughters on mothers.

\section{Discussion}

\section{Sex differences in PRP regression}

Significant positive correlations between PRPs of male and female siblings, from adults originating from Morocco and Britain (see Results), indicated that female offspring with long PRPs came from families in which their brothers has correspondingly long PRPs. This suggests that the genes regulating the time to onset of calling in females also regulate the length of the PRP in males. These genes can therefore be considered to control the rate of reproductive maturation in both sexes, as has previously been shown for Heliothis armigera (Colvin, 1990). In Swedish and Moroccan populations of $A$. gamma, males and females reach sexual maturity asynchronously, as has been shown for other noctuids (Wilson \& Gatehouse, 1992), which may be a mechanism to prevent inbreeding with close relatives.

\section{Geographical differences in PRP regulation}

Offspring of adults originating in Sweden differed from those of Moroccan and British insects. There was no significant correlation between the PRP of siblings, although these data were based on only six families. However, differences between Swedish insects and those from other areas have also been found in response to photoperiodic cues in insects collected in two successive years (Hill, 1991). This raises the possiblity that the Swedish sample was drawn from a different population from the British and Moroccan insects. Back-tracking techniques, which trace possible flight trajectories from meteorological records, suggest different over-wintering areas for Scandinavian and British populations of $A$. gamma (Mikkola \& Salmensuu, 1965; French, 1969; Hurst, 1969; Ryrholm \& Kallander, 1987; Lindfors et al., 1989). Although the formation of discrete geographical races would seem unlikely in such a mobile widespread species, different winter breeding areas may well cause some restriction in gene flow.

\section{Genetic regulation of PRP}

Sib-analysis and parent-offspring regressions revealed that the genes with the greatest influence on the length of the PRP are located on the X-chromosome (see Results). Low heritability estimates $(0.244 \pm 0.082)$ were obtained from regressions of mean PRP of daughters on those of their mothers (see Results), as is generally the case with $\mathrm{X}$-linked characters when the trait is measured in the heterogametic sex (Falconer, 1989). The significant regression of mean PRP of daughters on the PRPs of their mothers indicates autosomal influences, although this may also be due to non-genetic maternal effects. The genetic control of PRP has been shown to be strongly influenced by X-linked genes in other noctuids (Colvin, 1990; Wilson \& Gatehouse, 1992), with autosomal influences on the inheritance of female PRP also being apparent in Mythimna separata (Han \& Gatehouse, 1991a).

Differences in the rate of response to selection between the two experiments (Figs 1 and 2) can be explained by $\mathrm{X}$-linkage of genes and by differences in the procedures for establishing late and early-maturing lines. In the first selection experiment (Fig. 1), females in the parental generation were mated to males whose PRP was unknown. Early and late-maturing genes that were selected in parental females would have been carried by $G_{1}$ males and would not, therefore, be expressed in females until the $G_{2}$ generation. In the second selection experiment (Fig. 2), early and latematuring females were mated assortatively with males from early and late-maturing families. Therefore, most males that were mated to late-maturing females would themselves have carried genes coding for late maturity, which would be inherited by, and expressed in, $\mathrm{G}_{1}$ females.

Both the selection and the sib analysis experiments were carried out under short (12L:12D) photoperiods and at low temperatures. Under these environmental conditions, individuals extend their PRPs (Hill, 1991). By carrying out selection under these conditions it is therefore not possible to distinguish whether it is the length of PRP that is being selected or sensitivity to environmental cues. In either case, the major influence on the expression of the character under selection was from X-linked genes.

\section{Implications of $X$-linkage for migration}

Adults of $A$. gamma and other noctuid species make regular seasonal migrations into areas where they are 
unable to maintain permanent populations and the existence of return migrations to over-wintering sites has been questioned (Rabb \& Stinner, 1978; Stinner et al., 1983; but see Walker, 1980). There is, however, some evidence for southward return movement in autumn in A. gamma (Fisher, 1938) and also in other noctuids (Spitzer, 1972; Lingren et al., 1979). Furthermore, mark-and-capture experiments have provided unequivocal evidence of return migration over $800 \mathrm{~km}$ by $M$. separata in China ( $\mathrm{Li}$ et al., 1964). Han \& Gatehouse (1991a) suggested that X-linkage of genes regulating PRP may have been an essential pre-adaptation for the stability of migratory cycles in Mythimna separata, providing the potential for return migrations. They argued that X-linkage will minimize the frequencies of inappropriate alleles in populations at different latitudes because females (XY) will not carry genes for early-calling into northern regions. In $A$. gamma, $\mathrm{X}$-linkage of genes controlling PRP will ensure that most insects at any latitude will have the genetic constitution to return to southerly latitudes where continuous breeding is possible. Charlesworth et al., (1987) demonstrated that $\mathrm{X}$-linked characters have a decreased rate of fixation in response to directional selection compared with autosomally inherited characters. This may be important for $A$. gamma because fixation of PRP alleles must be avoided with the seasonally changing selection pressures experienced by migrants (Han \& Gatehouse, 1991a).

Variation in PRP in over-wintering populations will result in differential migration because individuals with longer PRPs will have potential to travel further and reach higher latitudes (termed genetic partitioning by Han \& Gatehouse, 1991a). There is some evidence for PRPs increasing with latitude in A. gamma because samples of insects from Britain and Germany $\left(50-53^{\circ} \mathrm{N}\right)$ have longer median PRPs than samples of insects collected in Morocco at $34^{\circ} \mathrm{N}$ (Hill, 1991). Environmental factors also influence PRP in noctuids (Han \& Gatehouse, 1991b) and, in A. gamma, PRPs are longer in decreasing and short photoperiods and at low temperatures (Hill \& Gatehouse, in press). The ability to respond to environmental cues that signal impending habitat deterioration, in conjunction with genes coding for later maturity, will further facilitate southward return migrations by individuals at high latitudes.

\section{Acknowledgements}

We would like to thank staff at the Station Experimental de la Direction de la Recherche Agronomique d'Afourer, Beni Mellal, Dr. Abdelhaq Hanafi (Institute Agronomique et Veterinaire Hassan II, Agadir), Dr M.
Hmimina (I.A.V. Hassan II, Rabat), Nils Ryrholm, Christer Solbreck and staff at Uppsala University Field Station, and Keith Hamer for help collecting insects. We also thank Jenny Shattock for help rearing insects and staff at Treborth Botanic Gardens for running light-traps throughout the period of study and providing larval food material. We also thank Ken Wilson and Keith Hamer for helpful comments on the manuscript. This research was supported by NERC grant number GR3/6570A.

\section{References}

BALACHOWSKy, A. S. 1972. Entomologie appliquée à agriculture. Lepidoptines, 2, 1145-1159.

BJOSTAD, L. B., GASTON, L. K. AND SHOREY, H. H. 1980. Temporal pattern of sex pheromone release by female Trichoplusia ni. J. Insect Physiol., 26, 493-498.

CALDWELl, R. L. AND HEGMANN, J. P. 1969. Heritability of flight duration in the milkweed bug Lygaeus kalmii. Nature, 223, 91-92.

CHARLESWORTH, B., COYNE, J. A. AND BARTON, N. H. 1987. The relative rates of evolution of sex chromosomes and autosomes. Am. Nat., 130, 113-146.

Colvin, J. C. 1990. Laboratory studies on the regulation of migration in the cotton bollworm. Heliothis armigera $(\mathrm{Hb}$. (Lepidoptera; Noctuidae) PhD Thesis, University of Wales. COLVIN, J. C. AND GATEHOUSE, A. G. 1993. The reproductionflight syndrome and the inheritance of tethered-flight activity in the cotton-bollworm moth. Heliothis armigera. Physiol. Entomol., 18(1).

DINGLE, H. AND EVANS, K. E. 1987. Responses in flight to selection on wing length in non-migratory milkweed bugs, Oncopeltus fasciatus. Entomol. Exp. Applic., 45, 289-296. FALCONER, D. S. 1989. Introduction to Quantitative Genetics. 3rd edn. Longman, London.

FISHER, K. 1938. Migrations of the Silver Y moth (Plusia gamma) in Great Britain. J. Anim. Ecol., 7, 230-247.

FRENCH, R. A. 1969. Migration of Laphygma exigua Hubner (Lepidoptera; Noctuidae) to the British Isles in relation to large scale weather systems. J. Anim. Ecol., 38, 199-210.

HAN, E. 1988. Laboratory studies on the regulation of migration in the Oriental armyworm Mythimna separata (Walker) (Lepidoptera; Noctuidae). PhD thesis, University of Wales.

HAN, E. AND GATEHOUSE, A. G. 1991a. Genetics of precalling period in the oriental armyworm, Mythimna separata (Walker) (Lepidoptera; Noctuidae), and implications for migration. Evolution, 45, 1502-1510.

HAN, E. AND GATEHOUSE, A. G. 1991b. Effect of temperature and photoperiod on the calling behaviour of a migratory insect, the oriental armyworm Mythimna separata. Physiol. Entomol., 16, 419-427.

HAN, E. AND GATEHOUSE, A. G. 1993. Flight capacity: genetic determination and physiological constraints in a migratory moth Mythimna separata. Physiol. Entomol.(in press). HILL, J. K. 1991. Regulation of migration and migratory strategy 
of Autographa gamma (L.) (Lepidoptera: Noctuidae). $\mathrm{PhD}$ thesis, University of Wales.

HILL, J. K. AND GATEHOUSE, A. G. 1993. Effects of temperature and photoperiod on development and pre-reproductive period of the silver Y moth Autographa gamma (Lepidoptera: Noctuidae). Bull. Entomol. Res., (in press).

HURST, G. W. 1969. Insect migrations to the British Isles. Quart. J. R. Meteorol. Soc., 95, 435-439.

Johnson, C. G. 1969. Migration and Dispersal of Insects by Flight. Methuen \& Co., Ltd, London.

LI, K., WONG, H.-H. AND woo, w.-s. 1964. Route of the seasonal migration of the oriental armyworm moth in the eastern part of China as indicated by a three year result of releasing and recapturing marked moths. (English summary.) Acta Phyto. Sin., 3, 101-110.

LINDFORS, C. E., MIKKOLA, K. AND AHTI, K. 1989. First record of Protexarnis squalida (Lepidoptera; Noctuidae) from Northern Europe with analysis of a long-range migration. Not. Entomol., 69, 5-12.

LINGREN, P. D., HENNEBERRY, T. J. AND SPARKS, A. N. 1979. Current knowledge and research on movement of the Cabbage Looper and related Looper species. In: Rabb, R. L. \& Kennedy, G. G. (eds). Movement of Highly Mobile Insects: Concepts and Methodology in Research. North Carolina State University, Raleigh, NC.

McANELLY, M. L. 1985. The adaptive significance and control of migratory behaviour in the grasshopper, Melanopus sanguipes. In: Rankin, M. A. (ed.) Migration: Mechanisms and Adaptive Significance. Contributions in Marine Science, vol. 27, Marine Science Institute, University of Texas at Austin.

MIKKOLA, K. AND SALMENSUU, P. 1965. Migration of Laphygma exigua Hb. (Lepidoptera; Noctuidae) in N. W. Europe in 1964. Ann. Zool. Fenn., 2, 124-139.

PAlMER, J. O. AND DINGLE, H. 1986. Direct and correlated responses to selection among life-history traits in milk- weed bugs (Oncopeltus fasciatus). Evolution, 40, 767-777.

PALMER, J. O. AND DINGLE, H. 1989. Responses of selection on flight behaviour in a migratory population of milkweed bugs (Oncopeltus fasciatus). Evolution, 43, 1805-1808.

PARKER, W. E. AND GATEHOUSE, A. G. 1985. Genetic factors controlling flight performance and migration in the African armyworm moth, Spodoptera exempta (Walker) (Lepidoptera; Noctuidae). Bull. Entomol. Res., 75, 49-63.

RABB, R. L. AND STINNER, R. E. 1978. The role of insect dispersal and migration in population processes. NASA Conf. Publ., 2070, 3-16.

RYRHOLM, N. AND KALLANDER, C. F. R. 1987. Autographa mandarina (Lepidoptera; Noctuidae) in eastern Sweden in 1985. (English summary) Entomol. Tidsk., 108, 130-134.

SPITZER, K. 1972. Seasonal adult activity of Scotia ipsilon Hfn. (Lepidoptera; Noctuidae) in Bohemia. Acta Entomol. Bohem., 69, 396-400.

STINNER, R. E., BARFIELD, C. S., STIMAC, J. L. AND DOHSE, L. 1983. Dispersal and movement of insect pests. Ann. Rev. Entomol., 28, 319-335.

szocs, G. AND тотн, м. 1979. Daily rhythm and age dependence of female calling behaviour and male responsiveness to sex pheromone in the gamma moth Autographa gamma (L.) (Lepidoptera; Noctuidae). Acta Phytopath. Acad. Sci. Hung., 14, 453-459.

TURGEON, J. J. AND MCNEIL, J. N. 1983. Modifications in the calling behaviour of Pseudaletia unipuncta (Lepidoptera; Noctuidae) induced by temperature conditions during pupal and adult development. Can. Entomol., 115, 1015-1022.

WALKER, T. J. 1980. Migrating lepidoptera: are butterflies better than moths? Fl. Entomol., 63, 79-98.

WLLSON, K. AND GATEHOUSEM A. G. 1992. Migration and genetics of the pre-reproductive period in the African armyworm moth, Spodoptera exempta. Heredity, 69, 255-262. 